\title{
TRANSFERÊNCIA DE IMUNIDADE PASSIVA EM EQUINOS: COMPORTAMENTO IMUNOLÓGICO DO RECÉM NASCIDO'
}

\author{
CARLA MARIA DE MEO SCOTONI ${ }^{2}$ \\ RAUL MACHADO NETO $^{3}$
}

RESUMO: O objetivo deste trabalho foi observar - comportamento imunológico de potros recémnascidos das raças Mangalarga e Anglo-Árabe no que se refere ao processo de aquisição de anticorpos maternos e sua correlação com os niveis de imunoglobulina do colostro. Foram utilizados 7 potros Anglo-Árabe e 6 potros Mangalarga para amostragem de sangue imediatamente após o nascimento (antes de qualquer ingestão de colostro), 24 e 48 horas, 5, 10, $15,20,25,30,40,50,60$ e 70 dias após 0 nascimento, e suas respectivas mães cujo colostro foi amostrado imediatamente após a parição, antes da primeira mamada. A quantificação das imunoglobulinas séricas foi efetuada pelo método do ZST (Zinc sulfate Turbidity) e para a análise dos resultados foram testados modelos matemáticos que estudam o processo em questão. Para a raça Mangalarga o modelo matemático foi: $y=23,9274-0,39766 x+6,467510^{-3}$ $\mathrm{x}^{2}$, com $\mathrm{r}=0,91$ e $\mathrm{P}<0,01$ e para a raça Anglo Árabe foi $y=34,161-0,756062 x+0,015604 x^{2}$

1 Parte da Dissertação apresentada pelo $1^{0}$ Autor à Escola Superior de Agricultura "Luiz de Queiroz"/USP, como parte das exigências para obtenção do grau de Mestre em Nutrição Animal e pastagens.

2 Engenheira Agrônoma, Mestre.

3 Professor Associado, Departamento de Zoologia, ESALQ/USP, Campus de Piracicaba. 
$-1,01310^{-3} x^{3}$, com $r=0,96$ e $P<0,05 . A$ concentração de IgG do colostro foi estimada com base na concentração de proteína total avaliada pelo método Micro-Kjeldhal. Este estudo permitiu concluir: (1) a presença de maior quantidade de IgG (imunoglobulina $G$ ) passiva no sangue dos potros, retardou o estabelecimento dos niveis normais de Ig (imunoglobulina $G+$ $M+A+E) ;(2)$ animais que adquiriram menor quantidade de IgG passiva apresentaram resposta mais intensa de produção endógena de Ig; (3) a concentração estimada de IgG no colostro apresentou correlação positiva com a concentração sérica dos potros no pico da absorção. Termos para Indexação: imunidade passiva, potro, colostro.

\section{PASSIVE IMMUNITY TRANSFERENCE IN EQUINUS: IMMUNOLOGICAL BEHAVIOUR OF THE NEW-BORN}

ABSTRACT: The objective of this work was to study the immunological behavior of newborn Mangalarga and Angle-Arabian foals, the acquiring process of maternal immunoglobulins and its correlation to the levels of colostral immunoglobulin. The Mangalarga and AngleArabian foals serum immunoglobulins were analysed by the ZST (zinc sulfate Turbidity) method. The results were tested by mathematical models which study the biological process of passibe immunity transfer in that period of observation: to the Mangalarga foals the tested model was: $Y=23.9274-0.39766 x+6.467510^{-3}$ $x^{2}$, with $r=0.91$ and $P<0.01$ to Angle-Arabian foals was: $y=34.161-0.756062 x+0.015604 x^{2}$ - $1.01310^{-3} \mathrm{x}^{3}$, with $r=0.96$ and $\mathrm{P}<0.05$. Estimation of the colostral IgG concentration was based on total protein concentration measured by Micro-Kjeldhal method. The results of this study allowed the following conclusions: (1) higher passive IgG in foals serum delayed the stablishment of normal Ig 
level; (2) animals which acquired lower quantities of passive IgG showed more intense response of endogenous Ig production;

(3) colostrum estimated IgG concentration showed positive correlation Serum IgG concentration of the foals at the point of maximal absorption showed positive correlation with colostrum estimated IgG.

Index Terms: passive immunity, foal, colostrum.

\section{INTRODUÇÃo}

Embora seja conhecida de longa data a necessidade de ingestão de colostro pelo recém-nascido para seu bom desenvolvimento, alguns pontos ainda permanecem obscuros, especialmente no caso de equinos, sobre o que pouco ou quase nada foi feito objetivando um melhor entendimento do processo de aquisição de imunidade passiva por esses animais.

Um componente importante do mecanismo de defesa dos mamíferos é sua capacidade de produzir anticorpos em resposta a microrganismos invasores e outras substâncias antigênicas. o ungulado nasce sem anticorpos circulantes e a proteção é conseguida através da transferência passiva de imunoglobulinas da mãe para o recém- nascido (EARLE, 1935; BRUNNER et alii; 1948; BRAMBELL, 1958; MORRIS, 1968; ROUSE, 1971, JEFFCOTT, 1971, 1972; SIMPSON-MORGAN \& SMEATON, 1972; OLIVEIRA et alii, 1980).

\section{Inúmeros estudos (BOYD,}

1972 ;

PLATT, 1973; JEFFCOTT, 1975; MCGUIRE et alii, 1975; TOWSEND et alii, 1983; LE BLANC et alii, 1986) sugeriram estreita relação entre morbidez e mortalidade de potros recém- nascidos e baixa concentração sérica de Ig derivadas do colostro.

A secreção de colostro é de curta duração e cai a niveis insignificantes em 24 horas após o parto. O potro geralmente mama o 
colostro durante as 2 ou 3 primeiras horas de vida e em 6 horas já se pode encontrar IgG (imunoglobulina $G$ ) no soro. O pico de IgG é atingido em 18 horas de vida, quando a concentração sérica é semelhante à do soro da mãe. Os anticorpos passivos declinam gradualmente até estarem completamente ausentes aos 5 meses de idade. Bem antes disso o potro já mostra sinais de estar apto a se proteger; Ig (imunoglobulina $G+M+A+E$ ) endógena é encontrada pela primeira vez com 2 semanas de idade, embora o nivel dos adultos não seja atingido até os 5 meses (JEFFCOTT, $1974 \mathrm{a}, 1974 \mathrm{~b}$, MCGUIRE et alii, 1977). JEFFCOTT (1974b) sugere que o pico de Ig endógena foi atingido mais cedo em potros que não receberam colostro, resultado que também é sugerido por MACHADO NETO \& PACKER (1986) trabalhando com bezerros.

A absorção de anticorpos pelo intestino delgado é semelhante em potros e bezerros (JEFFCOTT, 1972) . MACDOUGALL (1975) verificou uma eficiência de absorção de macromoléculas de $50 \pm 16,5 \%$ em bezerros, variando de 25 a 75\%, bem como uma alta correlação entre a quantidade de colostro fornecida e a quantidade de IgG absorvida, considerando uma concentração máxima de $250 \mathrm{~g}$ de IgG em 41 de colostro. JEFFCOTT (1975) nesse mesmo sentido obteve $22 \%$ de eficiência de absorção; ressaltando que essa eficiência se obtém sem considerar o "pool" extracelular de IgG.

\section{MATERIAL E MÉTODOS}

A fase de campo deste trabalho foi realizada no Haras Rancho Nativo, municipio de Limeira, Estado de São Paulo, e as análises laboratoriais foram efetuadas no Laboratório de Anatomia e Fisiologia Animal do Departamento de Zoologia da Escola Superior de Agricultura "Luiz de Queiroz", Campus de Piracicaba-USP. 
Foram utilizados 7 potros Anglo- Árabes e 6 potros Mangalarga para amostragem de sangue e suas respectivas mães para amostragem de colostro.

As amostras de sangue foram retiradas da veia jugular, aproximadamente $10 \mathrm{ml}$ por animal. O material foi recebido em tubo de centrífuga, centrifugado e o soro resultante transferido para dois frascos devidamente identificados e armazenados a $-20^{\circ} \mathrm{C}$ até a data da análise. As amostras foram coletadas imediatamente após o nascimento (antes da primeira mamada), às 24 e 48 horas, $5,10,15,20,25,30,40$, 50,60 e 70 dias após o nascimento. A quantificação das IgG séricas baseou-se no método descrito por MCEVAN (1970) que se refere à leitura espectrofotométrica da turvação obtida da reação das imunoglobulinas com sulfato de zinco $\left(\mathrm{ZnSO}_{4} \cdot 7 \mathrm{H}_{2} \mathrm{O}\right)$. Preparou-se a cada bateria de amostras uma nova solução de sulfato de $z$ inco Com $208 \mathrm{mg}$ de $\mathrm{ZnSO}_{4} \cdot 7 \mathrm{H}_{2} \mathrm{O}$ em $1.000 \mathrm{ml}$ de água destilada e fervida por 20 minutos, para evitar a presença de $\mathrm{CO}_{2}$ que influencia a turvação e consequentemente a densidade óptica. Todas as soluçōes utilizadas nesse método foram mantidas livres de $\mathrm{CO}_{2}$. Para isso montou-se um sistema com tubos de látex e pipetadores, de maneira que todo o ar consumido na operação borbulhava em solução de $\mathrm{NaOH}$ antes de entrar no circuito fechado.

A temperatura ambiente do laboratório foi mantida em $21^{\circ} \mathrm{C}$ durante as reações e leituras.

Procedeu-se a leitura da densidade óptica no espectrofotômetro (Coleman Junior II) em comprimento de onda de $660 \mathrm{~nm}$, após a adição de $100 \mathrm{ul}$ da amostra de soro a $6 \mathrm{ml}$ de sulfato de $z$ inco e incubação por 60 minutos. Utilizaram-se unidades ZST para expressar a concentração de anticorpos séricos (densidade óptica $x$ 100). Para estimar a concentração em $\mathrm{mg} / \mathrm{ml}$ foi obtida uma curva padrão da densidade óptica $x$ 
concentração de $\mathrm{Ig}(\mathrm{mg} / \mathrm{ml})$ determinada por Imunodifusào Radial, técnica descrita por MANCINI et alii (1965), utilizando-se amostras de soro de 8 potros recém-nascidos. A equação resultante foi $y=84,04 x-0,87$ onde $x$ = absorbância ou densidade óptica e $y=$ concentração de $\mathrm{Ig}$ em $\mathrm{mg} / \mathrm{ml}$, com coeficiente de correlação $r=0,88$.

A ocorrência de hemólise, que implicaria em erro na leitura da turvação, foi corrigido pela fórmula: $R=L-(A 54023)$, onde $R$ = concentração real de $\mathrm{Ig} \mathrm{em} \mathrm{mg} / \mathrm{ml}$, L = leitura da turvação em $660 \mathrm{~nm}$ convertida a $\mathrm{mg} / \mathrm{ml}$ e A540 = leitura da turvação em $540 \mathrm{~nm}$ do soro com diluição 1:20 (PFEIFFER, 1977). Para corrigir os dados obtidos em ZST para hemólise, foi calculada a porcentagem de correção resultante da fórmula anterior para dados em $\mathrm{mg} / \mathrm{ml}$.

Para análise dos resultados a relação entre período de amostragem e unidades ZST foi estudada por diferentes modelos matemáticos. A cada ponto de amostragem $(1,2 \ldots$ e 70 dias) as concentrações séricas de Ig foram analisadas para estudar o efeito da raça de acordo com o modelo inteiramente casualizado com diferentes números de repetiçōes.

\section{RESULTADOS E DISCUSSÃo}

A Figura 1 ilustra os resultados obtidos neste experimento quanto à concentração de Ig sérica de potros em relação à idade.

Após as 48 horas a relação entre periodo de coleta e unidades ZST para a raça Mangalarga é expressa pelo modelo matemático: $Y=23,9274-0,39766 \mathrm{x}+6,467510^{-3} \mathrm{x}^{2}$ (1), onde $x=$ período de coleta em dias e $y=$ unidades ZST com $r=0,91$ e $P<0,01$. A estimativa do ponto de mínimo foi de 30,7 dias, coincidente com o ponto de inflexão da curva (equação do $\left.2^{\circ} \mathrm{grau}\right)$, que pelos pontos observados ocor- 


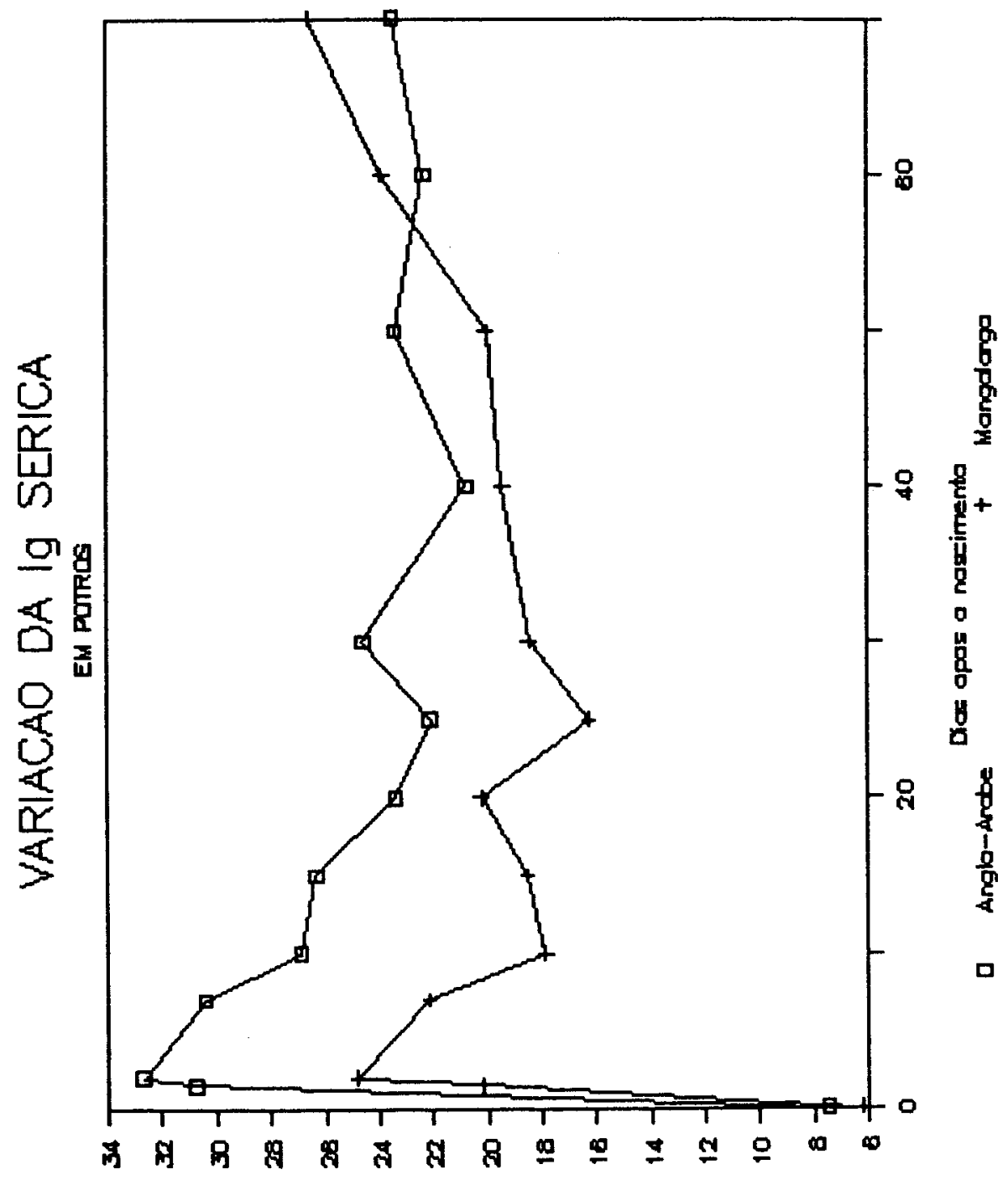

Lsz eepopjun

Figura 1 - Variação da Ig sérica (unidades ZST) em potros das raças Mangalarga e Anglo-Árabe. 
reu aos 30 dias. Na tentativa de discriminar os periodos experimentais, subdividiu-se o modelo (1), resultando em dois novos modelos de regressăo linear: $y=23,1995$ - 0,216542x (modelo 1a) de 2 a 30 dias, onde $Y=$ perfodo de coleta em dias $e x=$ unidades $\mathrm{ZST}, \operatorname{com} r=0,79$ e $\mathrm{P}<$ 0,05 .

O modelo para este periodo indica uma queda significativa $(P<0,05)$ de 0,2165 unidades ZST por dia até o $30^{\circ}$ dia que vem a ser o ponto de mínimo encontrado. o modelo $1 \mathrm{~b}, y=$ $8,39883+0,260439 x$, de 30 a 70 dias, onde $x=$ perlodo de coleta em dias e $Y=$ unidades $z S T$ com $r=0,98$ e $\mathrm{P}<0,01$ indica que aos 30 dias se iniciou uma fase significativa $(P<0,01)$ de aumento de 0,2604 unidades ZST por dia. Fisiologicamente $01^{\circ}$ periodo (2 a 30 dias) revela - pico de IgG sérica adquirida passivamente até as 48 horas de vida, o que corresponde a $80 \%$ da concentração média de animais adultos, seguida de uma fase de catabolismo até os 30 dias, quando pode-se considerar o inicio da fase de produção endógena maior que o catabolismo verificado no periodo anterior. A raça Mangalarga chegou aos 70 dias com uma quantidade considerável de Ig sérica, atingindo $86 \%$ da concentração média de animais adultos, ligeiramente superior à concentração máxima de IgG passivamente adquirida até as 48 horas.

Para a raça Anglo-Árabe a relação entre periodo de coleta e unidades 2ST é expressa pelo modelo $Y_{3}=34,161-0,756062 \mathrm{x}+0,015604 \mathrm{x}^{2}$ - $1,01310^{-3} x^{3}$ (2), onde $x=$ periodo de coleta em dias e $y=$ unidades ZST com $r=0,96$ e $P<$ 0,05 , que pode ser subdividido em $y=31,533$ $0,0288999 \times$ (modelo $2 a$ ) de 2 a 40 dias, onde $x$ = perlodo de coleta em dias e $y=$ unidades ZST com $\mathrm{r}=0,92$ e $\mathrm{P}<0,05$ e em $\mathrm{y}=19,8672+$ $0,0492596 \times$ (modelo $2 \mathrm{~b}$ ) de 40 a 70 dias onde $x$ = periodo de coleta em dias e $y=$ unidades ZST com $r=0,50$. Estas regressōes indicam um ponto de minimo aos 39 dias até o qual o modelo 2 a 
revela uma queda significativa $(P<0,05)$ de 0,2890 unidades ZST por dia, $e$ um ponto de inflexão aos 51 dias, diferente e posterior ao ponto de mínimo (equação do 39 grau). o modelo 2 b indica que após os 40 dias 0 acréscimo de unidades ZST não é significativo e até os 70 dias ainda não se observa uma relação linear entre as duas variáveis. Fisiologicamente revela-se uma fase de catabolismo das IgG dos 2 aos 40 dias, após o que pode-se considerar o inIcio da fase de produção endógena, uma vez que a concentração permanece praticamente constante até os 51 dias (ponto de inflexão) quando se observa tendência de ascensão da curva. o nível de Ig em Anglo-Árabes atingiu aos 70 dias, 65\% da concentração sérica de animais adultos, quantidade inferior à concentração máxima de IgG passivamente adquirida, que chega às 48 horas a 93\% da concentração do adulto. Essas considerações estão ilustradas no histograma da Figura 2.

E provável que a alta concentração de IgG materna presente na circulação dos potros Anglo-Árabes às 48 horas tenha retardado o inicio da fase endógena de produção de anticorpos em comparação com potros da raça Mangalarga, que apresentaram dentro do período observado uma fase de concentração da IgG sérica que não pode ser atribuida à absorção de imunoglobulinas do colostro. Esses resultados concordam com os trabalhos de PORTER (1979), RIBEIRO et alii (1983), e MACHADO NETO \& PACKER (1986). Embora os potros Anglo-Árabes ainda tenham um nivel sérico médio de IgG superior aos Mangalarga dentro do periodo observado, inclusive às 48 horas (pico de absorção), aos 70 dias de idade o nIvel sérico de Ig dos potros Mangalarga foi superior ao dos potros Anglo-Árabes.

A ausência de acréscimo significativo após o ponto de menor concentração encontrado para potros Anglo-Árabes pode também ter apresentado a interação dos processos de catabolis- 
Egua Mangalarga Adulta - 25,3 mg IgG/ml

Potro Mangalarga - 48 horas - 20,2 mg IgG/ml

$\square$ Potro Mlangalarga - 70 dias - $21,7 \mathrm{mg} \mathrm{Ig} / \mathrm{ml}$

Egua PSI adulta - 28,6 mg IgG/ml

周 Potro AA - 48 horas - 26,7 mg I gG/ml

Piil Potro AA - 70 dias - 18,6 mg Ig!/ml

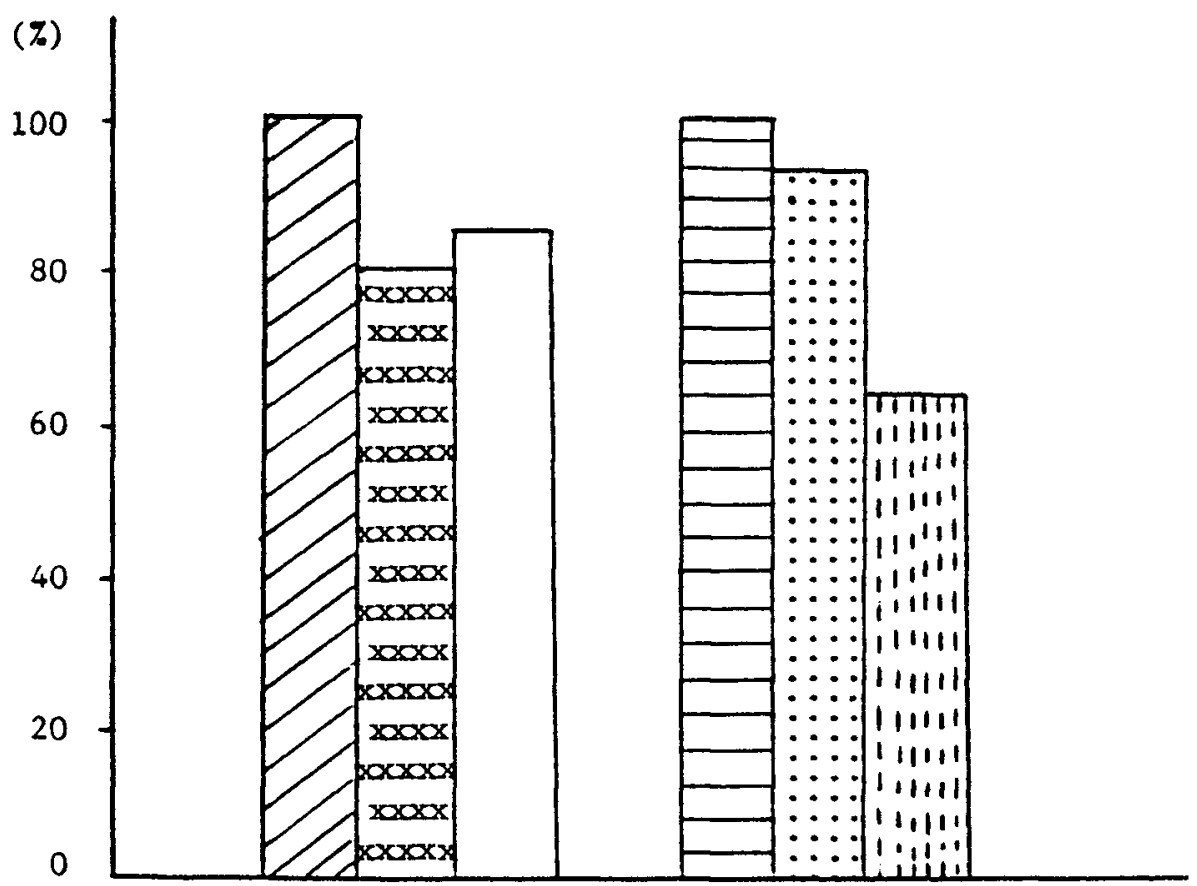

Figura 2 - Comparação do nível de Ig sérica de potros com o nível médio de adulto. 
mo das Ig absorvidas e de produção endógena de Ig, de maneira que não foi possivel caracterizar o ponto de inflexão da curva e, consequentemente, o início da fase endógena no período observado.

Observando-se a Figura 1 verifica-se que a concentração de IgG sérica dos potros Anglo-Árabes se mantém significativamente superior à concentração dos potros Mangalarga até os 10 dias, período onde a variação da concentração sérica de IgG é exclusivamente devida à IgG exógena (passiva), proveniente do colostro. Aos 30 dias, época em que se caracteriza o início da fase de produção de Ig endógenas na raça Mangalarga, a concentração dessa raça se mantém significativamente inferior, quadro que se inverte aos 70 dias, quando a concentração de Ig sérica dos Mangalarga está em ascensão e passa a ser significativamente superior, enquanto que nos potros Anglo- Árabes o catabolismo da IgG exógena e a produção de Ig endógenas se equivalem, adiando a caracterização da fase de produção.

Ainda foi possivel observar que o coeficiente de variação (CV) tendeu a se reduzir nos períodos mais avançados de amostragem, indicando que há um menor número de variáveis envolvidas na fase endógena de produção de Ig (Tabela 1).

Determinada a proteína total do colostro, é possível estimar a concentração de IgG. Considerando-se IgG $(\mathrm{mg} / \mathrm{ml})=40 \% \mathrm{da} \mathrm{PT}$ do colostro (ROUSE \& INGRAM, 1970) e a concentração sérica dos potros no pico de absorção (24 e 48 horas) obtida neste estu- do chegamos aos resultados das tabelas 2 e 3 .

Com base nas considerações anteriores, obtivemos média de $87,80 \mathrm{mg} \mathrm{IgG} / \mathrm{ml}$ de colostro em éguas PSI, superior $(P<0,01)$ à média de $46,57 \mathrm{mg}$ IgG/ml em éguas Mangalarga e consequentemente média de $28,17 \mathrm{mg} \mathrm{IgG} / \mathrm{ml}$ de soro para potros Anglo-Árabes no pico de absor- 
Tabela 1. Análise da variáncia para estudo do efeito de raça na concentração de Ig sérica de potros nos diferentes pontos de amostragem.

\begin{tabular}{|c|c|c|c|c|c|c|c|}
\hline \multirow[b]{2}{*}{ Causa da } & \multirow[b]{2}{*}{ Variação } & \multirow[b]{2}{*}{$\mathrm{GL}$} & \multirow[b]{2}{*}{ QM } & \multirow[b]{2}{*}{ PROB } & \multirow[b]{2}{*}{$\mathrm{CV}(8)$} & \multirow{2}{*}{$\frac{\text { Médias }}{A A}$} & \multirow{2}{*}{$\frac{(\mathrm{mg} / \mathrm{ml})}{\mathrm{ML}}$} \\
\hline & & & & & & & \\
\hline 1 dia & $\begin{array}{l}\text { Raça } \\
\text { ResIduo }\end{array}$ & $\begin{array}{l}1 \\
9\end{array}$ & $\begin{array}{r}309,82 \\
78,23\end{array}$ & 0,07 & 33,87 & $\begin{array}{l}30,96 \\
26,50\end{array}$ & $\begin{array}{l}20,23 \\
17,77\end{array}$ \\
\hline 2 dias & $\begin{array}{l}\text { Raça } \\
\text { Residuo }\end{array}$ & $\begin{array}{l}1 \\
7\end{array}$ & $\begin{array}{r}126,67 \\
34,65\end{array}$ & 0,09 & 21,25 & $\begin{array}{l}33,00 \\
26,78\end{array}$ & $\begin{array}{l}25,04 \\
20,18\end{array}$ \\
\hline 5 dias & $\begin{array}{l}\text { Raça } \\
\text { Residuo }\end{array}$ & $\begin{array}{l}1 \\
9\end{array}$ & $\begin{array}{r}202,88 \\
15,00\end{array}$ & 0,005 & 14,86 & $\begin{array}{l}30,63 \\
24,87\end{array}$ & $\begin{array}{l}22,00 \\
17,62\end{array}$ \\
\hline 10 dias & $\begin{array}{l}\text { Raça } \\
\text { Residuo }\end{array}$ & $\begin{array}{l}1 \\
9\end{array}$ & $\begin{array}{r}240,55 \\
13,11\end{array}$ & 0,002 & 15,56 & $\begin{array}{l}27,54 \\
28,78\end{array}$ & $\begin{array}{l}18,15 \\
14,39\end{array}$ \\
\hline 15 dias & $\begin{array}{l}\text { Raça } \\
\text { Resíduo }\end{array}$ & $\begin{array}{l}1 \\
8\end{array}$ & $\begin{array}{r}174,31 \\
53,09\end{array}$ & 0,10 & 32,13 & $\begin{array}{l}26,00 \\
20,94\end{array}$ & $\begin{array}{l}18,50 \\
14,68\end{array}$ \\
\hline 20 dias & $\begin{array}{l}\text { Raça } \\
\text { Residuo }\end{array}$ & $\begin{array}{l}1 \\
9\end{array}$ & $\begin{array}{l}29,40 \\
43,54\end{array}$ & 0,56 & 28,87 & $\begin{array}{l}23,58 \\
18,95\end{array}$ & $\begin{array}{l}20,30 \\
16,19\end{array}$ \\
\hline 25 dias & $\begin{array}{l}\text { Raça } \\
\text { Residuo }\end{array}$ & $\begin{array}{r}1 \\
10\end{array}$ & $\begin{array}{l}44,85 \\
31,15\end{array}$ & 0,25 & 26,66 & $\begin{array}{l}22,57 \\
18,10\end{array}$ & $\begin{array}{l}18,65 \\
14,80\end{array}$ \\
\hline 30 dias & $\begin{array}{l}\text { Raça } \\
\text { Resíduo }\end{array}$ & $\begin{array}{l}1 \\
9\end{array}$ & $\begin{array}{r}186,37 \\
15,50\end{array}$ & 0,007 & 19,36 & $\begin{array}{l}24,00 \\
19,34\end{array}$ & $\begin{array}{l}16,58 \\
13,07\end{array}$ \\
\hline 40 dias & $\begin{array}{l}\text { Raça } \\
\text { Residuo }\end{array}$ & $\begin{array}{r}1 \\
10\end{array}$ & $\begin{array}{r}9,98 \\
10,73\end{array}$ & 0,64 & 16,19 & $\begin{array}{l}21,00 \\
16,78\end{array}$ & $\begin{array}{l}19,15 \\
15,23\end{array}$ \\
\hline 50 dias & $\begin{array}{l}\text { Raça } \\
\text { Residuo }\end{array}$ & $\begin{array}{r}1 \\
11\end{array}$ & $\begin{array}{r}48,81 \\
107,77\end{array}$ & 0,04 & 14,14 & $\begin{array}{l}23,93 \\
19,24\end{array}$ & $\begin{array}{l}20,04 \\
25,98\end{array}$ \\
\hline 60 dias & $\begin{array}{l}\text { Raça } \\
\text { ResIduo }\end{array}$ & $\begin{array}{r}1 \\
10\end{array}$ & $\begin{array}{l}13,60 \\
19,32\end{array}$ & 0,60 & 18,06 & $\begin{array}{l}22,29 \\
17,75\end{array}$ & $\begin{array}{l}24,30 \\
19,53\end{array}$ \\
\hline 70 dias & $\begin{array}{l}\text { Raça } \\
\text { Residuo }\end{array}$ & $\begin{array}{r}1 \\
11\end{array}$ & $\begin{array}{r}46,44 \\
6,76\end{array}$ & 0,02 & 10,40 & $\begin{array}{l}23,32 \\
18,66\end{array}$ & $\begin{array}{l}27,13 \\
21,85\end{array}$ \\
\hline
\end{tabular}

GL = graus de 1 iberdade

$\mathrm{QM}=$ quadrado médio

$C V=$ coeficiente de variação

$A A=$ Anglo-Árabe .

ML = Mangalarga

PROB = NIvel numérico de Significância 
Tabela 2. Niveis de IgG do colostro de éguas PSI e de IgG sêrica em potros da raça Anglo-Árabe no pico de absorção.

\begin{tabular}{cccc}
\hline No. ANIMAL & $\begin{array}{c}\text { IgG COLOSTRO } \\
(\mathrm{mg} / \mathrm{ml})\end{array}$ & No. ANIMAL & $\begin{array}{c}\text { IgG COLOSTRO } \\
(\mathrm{mg} / \mathrm{m} \mathrm{l})\end{array}$ \\
\hline E4 & 84,88 & $\mathrm{P} 4$ & $31,28(24 \mathrm{~h})$ \\
E5 & 75,12 & P5 & $25,33(24 \mathrm{~h})$ \\
E6 & 92,64 & P6 & $21,82(24 \mathrm{~h})$ \\
E8 & 95,25 & P8 & $29,15(24 \mathrm{~h})$ \\
E10 & 91,16 & P10 & $33,25(24 \mathrm{~h})$ \\
\hline
\end{tabular}

Tabela 3. Níveis de IgG do colostro e de IgG sérica em potros da raça Mangalarga no pico de absorção.

\begin{tabular}{cccc}
\hline No. ANIMAL & $\begin{array}{c}\text { IgG colostRo } \\
(\mathrm{mg} / \mathrm{m} 1)\end{array}$ & No. ANIMAL & $\begin{array}{c}\text { IgG ColostRo } \\
(\mathrm{mg} / \mathrm{ml})\end{array}$ \\
\hline E1 & 31,44 & P1 & $26,23(48 \mathrm{~h})$ \\
E3 & 27,84 & P3 & $15,52(24 \mathrm{~h})$ \\
E7 & 35,92 & P7 & $17,08(24 \mathrm{~h})$ \\
E13 & 45,20 & P13 & $17,62(48 \mathrm{~h})$ \\
E14 & 92,44 & P14 & $24,76(48 \mathrm{~h})$ \\
\hline
\end{tabular}


ção, superior $(P<0,01)$, segundo a análise da variância, à média de $20,24 \mathrm{mg} \mathrm{IgG} / \mathrm{ml}$ de soro para potros Mangalarga.

A correlação entre a concentração de IgG no colostro e no sangue dos potros no pico de absorção foi de 0,69 ( $P<0,05)$.

\section{CONCLUSÕES}

Os resultados deste trabalho permitiram estabelecer as seguintes conclusões:

1. A concentração sérica de IgG nos potros no pico de absorção (24 e 48 horas) apresentou alta correlação com a quantidade estimada de IgG no colostro.

2. A maior quantidade de IgG passiva presente no sangue dos potros Anglo-Árabes nos primeiros dias retardou o estabelecimento de niveis semelhantes aos dos adultos.

3. Sob as mesmas condições de desafio imunológico, animais com menor concentração sérica de IgG passiva apresentaram resposta maisintensa de produção de Ig, como a que se observou com potros Mangalarga. 


\section{REFERENCIAS BIBLIOGRÁFICAS}

BOYD, J.W. The relationship between serum immunoglobulin deficiency and disease in calves: a farm survey. Veterinary Record, London, 90 (23): 645-49, jun. 1972 .

BRAMBELL, J.W.R. The passive immunity of the young mammal. Biological Reviews, Cambridge, 33: 488-531, 1958 .

BRUNNER, D.W., EDWARDS, P.R., DOLL, E.R. Passive immunity in the newborn foal. Cornell Veterinarian, Ithaca, 38: 363-66, 1948 .

EARLE, J.P. Influence of the ingestion of colostrum on proteins of the blood sera of young foals, kids, lambs and pigs. Journal of Agricultural Research, Washington, DC, 51: 479-91, set. 1935 .

JEFFCOTT, L.B. Duration of permeability of the intestine to macromolecules in the newly-born foal. Veterinary Record, London, 88: 340-41, mar. 1971.

JEFFCOTT, L.B. Passive immunity and its transfer with special reference to the horse. Biological Reviews, Cambridge, 47: 439-64, 1972 .

JEFFCOTT, L.B. Some practical aspects of the transfer of passive immunity to newborn foals. Equine Veterinary Journal, London, 6 $(3)$ : 105-15, jul. 1974a.

JEFFCOTT, L.B. studies on passive immunity in the foal. Journal of Comparative Pathology and Therapentics, London, 84:93$101,1974 \mathrm{a}$. 
JEFFCOTT, L.B. The transfer of passive immunity to the foal and its relation to immune status after birth. Journal of Reproduction Fertility, Oxford, 23: 727733, 1975 .

LE BLANC, M.M., MCLAURIN, B.I., BOSWELL, R. Relationship among serum immunoglobulin concentration in foals, colostral specific gravity and colostral immunoglobulin concentration. Journal of American Veterinary Medical Association, Chicago, 189(1): jul. 1986.

Mac DOUGALL, D.F. Immunoglobulin metabolism in the neonatal foal. Journal of Reproduction and Fertility, oxford, 23: $739-42,1975$.

MACHADO NETO, R. \& PACKER, I.U. Flutuação de imunoglobulina sérica em bezerros da raça holandesa submetidos a diferentes regimes de aleitamento. Revista da Sociedade Brasileira de Zootecnia, Viçosa, 15(5): $439-47,1986$.

MANCINI, G., CARBONARA, A.O., HEREMANS, V.E. Immunochemical quantification of antigens by single radial immunodifusion. Immunochemistry, London, $\underline{2}$ : 235-254, 1965.

MC EVAN, A.D., FISHER, E.W., SELMAN, T.E., PENHALE, W.I. A turbity test for the estimation of immunoglobulin levels in neonatal calf serum. Clinica Chemica Acta, Amsterdam, 27: 155-63, 1970.

MC GUIRE, T.C., PORRIE, M.J., BANKS, R. Hypogamaglobulinemia predisposing to infections in foals. Journal of American Veterinary Medical Association, Chicago, 166 (1): 71-5, jan. 1975 . 
MC GUIRE, T.C., CRAWFORD, T.B., HOLLOWELL, A.L., MACOMBER, L.E. of colostral immunoglobulin transfer as one explanation for most infections and deaths of neonatal foals. Journal of American Veterinary Medical Association, Chicago, 170 (11): 1302-4, jun. 1977.

MORRIS, F.G. Gamaglobuline absorption in the newborn. In: CODE, C.F. Handbook of physiology alimentory canal. American Physiological Society, Baltimore, 3 : 1491$512,1968$.

OLIVEIRA, F.R.A.P. de, GACER, F., CURY, L., AUGUSTO, C., LEÃO, J.F.S. Evolução do perfil do soro protéico em asininos e muares durante o desenvolvimento. Boletim da Indústria Animal, Nova Odessa, 37: 24666,1980 .

PFEIFFER, N.E., MC GUIRE, T.C., BELDEL, R.B., WEIKEL, J.M. Quantitation of bovine immunoglobulin comparison of single radial immunodifusion, zinc sulfate turbidity, serum electrophoresis and refractometer methods. American Journal Veterinary Research, Chicago, 38(5): 693-98, 1977.

PORTER, P. Adoptive immunization of neonate by breast factors. In: OGRA, P.L. \& DAYTON, D. Immunology of Breast Milk. New York, Raven Press, p. 127-206, 1979.

PLATT, H. Septicemia in the foal. British Veterinary Journal, London, 129: 221-29, 1973. 
RIBEIRO, M.F.M., BELEM, P.A.D., PARROYO, J. H., FARIA, V.P. de. Hipogamaglobulinemia em bezerros. Arquivo Brasileiro de Medicina Veterinária e Zootecnia, Belo Horizonte, $\underline{35}(4): 537-46,1983$.

ROUSE, B.T. \& INGRAM, D.G. The total protein and immunoglobulin profile of equine colostrum and milk. Immunology, oxford, 19:901-907, 1970 .

ROUSE, B.T. The immunoglobulins of adult equine and foal sera: a quantitative study. British Veterinary Journal, London, 127:45-52, 1971 .

SIMPSON-MORGAN, M.W. \& SMEATON, T.C. The transfer of antibodies by neonates and adults. Advances in veterinary science and Comparative Medicine, San Diego, 16: 35583,1972 .

TOWSEND, H.G.G., TABEL, H., BRISTOL, F.M. Induction of parturition in mares: effect on passive transfer of immunity to foals. Journal of American Veterinary Medical Association, Chicago, 182(3): 255-57, fev. 1983 .

Trabalho entregue para publicação em 27.09.91 Trabalho aprovado para publicação em 05.11.91 